Running head: ATTACHMENT AND FEEDBACK-SEEKING

Adult Attachment and Feedback-Seeking Patterns in Relationships and Work

\author{
Erica G. Hepper Katherine B. Carnelley \\ University of Southampton
}

This is the pre-peer reviewed version of the following article:

Hepper, E. G., \& Carnelley, K. B. (2010). Adult attachment and feedback-seeking patterns in relationships and work. European Journal of Social Psychology, 40, 448464.

The article is published by Wiley-Blackwell and is available in final form at http://www3.interscience.wiley.com/journal/1823/home

Correspondence should be addressed to:

Erica G. Hepper, Ph.D.

School of Psychology

University of Southampton

Highfield, Southampton

SO17 1BJ

United Kingdom

Email: E.Hepper@soton.ac.uk

Tel: +44 2380594584

Fax: +44 2380593328 


\begin{abstract}
Adults with different attachment orientations rely on different areas of life to maintain self-views. This paper reports two studies that examine the link between attachment and feedback-seeking patterns in interpersonal and competence-related domains.

Participants in Study 1 imagined receiving feedback from a friend. Participants in Study 2 completed dyadic tasks and were promised feedback from interpersonal- and competence-relevant sources. Across both studies, secure individuals consistently chose the most positive feedback. Individuals high in attachment avoidance sought negative feedback over positive, although dismissing-avoidant individuals sought positive hypothetical feedback about autonomy. Study 2 further suggested that highly avoidant individuals were more open to negative feedback than positive feedback and than were secure individuals. Moreover, individuals high in attachment anxiety failed to seek positive interpersonal feedback but pursued interpersonal over competence feedback. Results highlight the role of feedback-seeking in maintenance of positive or negative self-views for adults with different attachment orientations.
\end{abstract}

Keywords: Attachment, self-views, feedback-seeking, sources of self-esteem 


\section{Adult Attachment and Feedback-Seeking Patterns in Relationships and Work}

Individuals with different attachment orientations possess self-concepts differing in valence and structure. These differences are thought to originate in early caregiving experiences. But how do they persist into adulthood? One important process by which the self is maintained and developed is receiving self-relevant feedback from others. Feedback provides vital information about strengths and weaknesses, and people often go out of their way to seek it. Seeking particular feedback influences the information one receives in return, contributing to self-concept maintenance and change. In the present research, we examine the ways in which attachment orientation influences feedback-seeking in important areas of life. In so doing, we aim to shed light on the ways that insecure individuals maintain negative self-views.

Attachment, Affect-Regulation, and Sources of Self-Worth

According to attachment theory (Bowlby, 1969, 1973, 1980), people's early caregiving experiences shape the way they mentally represent the self and relationships, and the strategies they use to navigate the social world throughout the lifespan (known as attachment orientation; Ainsworth, Blehar, Waters, \& Wall, 1978; Bartholomew \& Horowitz, 1991). In adulthood, secure adults possess more positive, coherent, and stable self-representations than insecure adults (Foster, Kernis, \& Goldman, 2007; Mikulincer, 1995). One reason is that people with varying attachment histories develop different affect-regulation strategies (Mikulincer, Shaver, \& Pereg, 2003) and rely on different sources for feelings of self-worth (Brennan \& Morris, 1997). We outline this logic next.

Infants whose caregivers are consistently responsive learn to regulate emotions internally and explore confidently: a secure attachment orientation. Secure infants develop an internal secure base and positive mental models of self and others, which 
maintain their high self-esteem throughout life (Mikulincer \& Shaver, 2004; Mikulincer et al., 2003). Infants who lack this caregiving environment cannot develop a secure base, so adopt secondary strategies for maintaining self-esteem. Attachment insecurity is defined with two dimensions: avoidance of intimacy and anxiety about abandonment (Brennan, Clark, \& Shaver, 1998). Each is characterised by different strategies. Infants whose caregivers are rejecting develop negative models of others, suppress negative affect, and "deactivate" their attachment system: they become high in attachment avoidance. High-avoidant people deny the importance of relationships and derive high self-esteem from skills and independence. However, this self-esteem is defensive and may obscure underlying self-doubts (Fraley, Davis, \& Shaver, 1998; Mikulincer, Dolev, \& Shaver, 2004). Conversely, infants whose caregivers are inconsistent develop negative models of the self, experience strong negative affect, and "hyperactivate" their attachment system: they become high in attachment anxiety. Highanxious people rely on others' approval and affection for self-worth. However, they need constant reassurance so lack self-esteem (Shaver, Schachner, \& Mikulincer, 2005). Combinations of high versus low attachment anxiety and avoidance are often used to define categorical attachment styles (Brennan et al., 1998). Secure adults are low in both; dismissing adults are high in avoidance but low in anxiety; preoccupied adults are high in anxiety but low in avoidance; and fearful adults are high in both. Here, we use these labels to aid interpretation, but the dimensions of anxiety and avoidance more accurately characterise individual differences (Fraley \& Waller, 1998).

Three studies have shown links between attachment orientations and sources of self-worth. First, Brennan and Morris (1997) found that secure attachment was predicted by high self-liking (based on internalised love and approval), preoccupied and 
fearful attachment were predicted by low self-liking, and dismissing attachment was predicted by high self-competence (based on mastery and independence; Tafarodi \& Swann, 2001). Second, Brennan and Bosson (1998) found that the high self-esteem of secure (vs. fearful) individuals was mediated by relationship well-being, whereas the high self-esteem of dismissing (vs. preoccupied) individuals was mediated by mastery and independence. Finally, Park, Crocker, and Mickelson (2004) found that secure individuals reported basing self-worth on family support (reflecting a secure base), preoccupied and fearful individuals reported relying on physical appearance and approval (reflecting dependence on others), and dismissing individuals denied relying on any sources (reflecting defensive need for self-reliance). Thus, as proposed, attachment anxiety is linked to interpersonal sources of self-esteem, whereas attachment avoidance is linked to agentic sources of self-esteem.

Attachment differences in sources of self-esteem have important consequences in adulthood. High-anxious people's over-dependence on others and high-avoidant people's excessive self-reliance have been implicated in their vulnerability to depression (Wei, Mallinckrodt, Russell, \& Abraham, 2004; Zuroff \& Fitzpatrick, 1995), poor relationship functioning (Campbell, Simpson, Boldry, \& Kashy, 2005; Feeney, 1999), and work problems (Hardy \& Barkham, 1994; Hazan \& Shaver, 1990). Thus, secondary sources of self-esteem are not healthy. Given the dynamic nature of the self, it is crucial to understand better the mechanisms that maintain these self-concept differences.

\section{Attachment and Feedback-Seeking}

One important way that people regulate self-views in personally relevant domains is by seeking feedback. Feedback may include verbal and non-verbal cues from others, success or failure on tasks, or social comparisons. Self-view maintenance is 
motivated: People seek feedback frequently in everyday life (Taylor, Neter, \& Wayment, 1995). Given that one's attachment orientation influences the areas from which one derives self-worth, it might also influence the feedback one seeks about those areas. One important behaviour is selectively seeking out either positive or negative feedback. That is, one can interact with people who view one favourably or unfavourably, ask positive or negative leading questions, and undertake tasks with a higher or lower probability of success. Thus, in this research we begin by considering how attachment orientations influence the extent to which one tends to seek out positive versus negative feedback; we refer to this as positivity of selective feedback-seeking.

Generally, people are motivated to seek positive feedback in order to attain positive self-views (i.e., self-enhance), especially regarding a personal source of selfworth (Crocker \& Wolfe, 2001; Sedikides \& Strube, 1997). However, people with higher self-esteem self-enhance more than those with lower self-esteem (Sedikides \& Gregg, 2003; Tice, 1991). This is important because the feedback one tends to seek colours the feedback (e.g., positive or negative) that one receives. In addition, seeking negative feedback is associated with depression and may lead others to view one negatively (Swann, Rentfrow, \& Guinn, 2003). Thus, seeking positive (vs. negative) feedback may be more adaptive for maintaining self-esteem and esteem from others.

Given the link between attachment anxiety and self-esteem (Bartholomew \& Horowitz, 1991), secure and dismissing individuals (who have high self-esteem) might seek positive feedback in personally important areas to a greater extent than fearful and preoccupied individuals (who have low self-esteem). Prior research addressing this question is limited to interpersonal feedback, which is more self-relevant for people with high (vs. low) attachment anxiety. Cassidy, Ziv, Mehta, and Feeney (2003) 
reported that secure (vs. insecure) children and adolescents were more likely to seek positive feedback from peers, a link mediated by global self-worth. Three studies (Brennan \& Bosson, 1998; Brennan \& Morris, 1997; Carnelley, Israel, \& Brennan, 2007) showed that secure adults hypothetically chose to hear more positive feedback from a romantic partner than did adults with other attachment styles. Overall, these results support the notion that secure individuals have the most adaptive (i.e., positive) approach to feedback-seeking in romantic relationships. However, individuals also receive important feedback from people other than romantic partners.

The above research suggests that dismissing people, despite their high selfesteem, seek negative feedback from romantic partners (consistent with relationships not being self-relevant). However, given that high-avoidant individuals derive selfesteem from competence and self-reliance, dismissing people should self-enhance by seeking positive feedback in agentic, not interpersonal domains. It is also important to understand how fearful individuals (who are high in avoidance but low in self-esteem) approach agentic feedback. No research has yet examined the role of attachment in seeking feedback from non-romantic others or about self-competence. Given that people with different attachment orientations derive self-worth from different areas of life, it is crucial to do so. The present research was designed to address this omission.

\section{Overview of the Present Research}

In this research, we examined the feedback-seeking patterns of individuals with different attachment orientations. We extended prior research by examining feedback that was (a) about both interpersonal and competence attributes, (b) from non-romantic sources, and (c) both hypothetical and real. In Study 1, participants imagined receiving feedback about various domains from a friend. Two domains were interpersonal: close 
relationships (ability to form and maintain intimate relationships) and social acceptance (inclusion and likeability in social interactions). Two domains were agentic: mastery (individual ability to meet personal goals) and autonomy (relative dependence on oneself, not other people). In Study 2, participants completed interpersonal and agentic tasks and were offered real feedback about the same attributes. In both studies, participants selected the feedback (from positive and negative options) that they preferred to receive in each domain. In Study 2, we also assessed openness to positive and negative feedback in each domain and choice of domain (interpersonal vs. competence). Overall, we aimed to shed new light on the ways that individuals with different attachment patterns maintain and develop self-views in different areas of life.

Study 1

\section{Hypotheses: Attachment and Positivity of Selective Feedback-Seeking}

Two factors affect self-enhancement via feedback-seeking: self-relevance of domain (i.e., motivation to self-enhance) and self-esteem (i.e., ability to self-enhance). In domains of low self-relevance, people are not motivated to self-enhance, so selfesteem does not affect feedback-seeking. In domains of high self-relevance, people are motivated to self-enhance, so self-esteem influences their ability to seek out positive feedback. Our hypotheses, summarised in Table 1, reflect this combination of factors.

Interpersonal domains are highly self-relevant for preoccupied and fearful individuals, and fairly self-relevant for secure individuals. All three groups should thus be motivated to self-enhance, but secure individuals should seek more positive feedback than preoccupied and fearful individuals because of their higher self-esteem. Dismissing individuals deny the importance of relationships, so are not motivated to self-enhance. Thus, conceptually replicating prior studies with a non-romantic target, we expected 
attachment anxiety and avoidance to be negatively associated with feedback-seeking positivity in the domains of relationships and acceptance (Hypothesis 1).

Competence domains are highly self-relevant for dismissing and fearful individuals, and moderately relevant for secure individuals. All three groups should thus be motivated to self-enhance, but dismissing and secure individuals should seek more positive feedback than fearful individuals because of their higher self-esteem. Preoccupied individuals are not motivated to self-enhance because competence is not self-relevant. Thus, in a novel hypothesis, we expected attachment anxiety (but not avoidance) to be negatively associated with feedback-seeking positivity in the domains of mastery and autonomy (Hypothesis 2).

\section{Hypotheses: The Role of Self-Esteem}

Cassidy et al.'s (2003) findings suggest that self-esteem mediates attachment differences in positivity of feedback-seeking. However, attachment differences in selfconcept and behaviour are more complex than valence, and have previously been independent of self-esteem (e.g., reactions to partner behaviour; Collins, Ford, Guichard, \& Allard, 2006; coping with stress; Mikulincer \& Florian, 1998). We thus predicted that attachment differences in feedback-seeking would not be explained solely by self-esteem (Hypothesis 3).

\section{Method}

\section{Participants}

In total 302 individuals participated (78\% female; $M_{\mathrm{AGE}}=18.7, S D=1.94$, range 16-25). They comprised students and graduates of a British university $(n=177)$ and sixth-form college students aged 16-18 $(n=125)$, who participated voluntarily or for course credit. Half $(53 \%)$ were in a romantic relationship $\left(M_{\text {DURATION }}=18\right.$ months $)$. 


\section{Materials and Procedure}

Participants either participated in a classroom or in private. They completed two questionnaire packets; the first contained measures of attachment and self-esteem (counterbalanced), the second an unrelated filler measure (about leisure activities) and the feedback-seeking measure. Afterward, participants were thanked and debriefed.

Attachment. The Experiences in Close Relationships scale (ECR; Brennan et al., 1998) assesses attachment orientation across general romantic relationship experiences. Two 18-item subscales assess anxiety (e.g., "I worry about being abandoned"; $\alpha=.90$ ) and avoidance (e.g., "I prefer not to show a partner how I feel deep down”; $\alpha=.95$ ). Items were rated from 1 (strongly disagree) to 7 (strongly agree). The ECR has been used extensively and has shown excellent validity (Shaver \& Mikulincer, 2004). The subscales were weakly correlated in the present sample $(r=.11, p=.06)$.

Self-Esteem. The Self-Liking/Competence Scale Revised (SLCS-R; Tafarodi \& Swann, 2001) assesses global self-esteem with 16 items, half measuring self-liking (e.g., "I am comfortable with myself") and half self-competence (e.g., "I perform well at many things"). Items were rated from 1 (strongly disagree) to 5 (strongly agree). We averaged all items to assess self-esteem $(\alpha=.91)$.

Hypothetical feedback-seeking. An adapted Feedback-Seeking Questionnaire (Swann, Wenzlaff, Krull, \& Pelham, 1992) assessed positivity of selective feedbackseeking in the domains of close relationships, social acceptance, mastery, and autonomy. Participants were asked to imagine a same-sex friend answering questions about the participant, and were shown three positive and three negative leading questions in each domain. Examples for close relationships are "What makes this person particularly good at maintaining close relationships?" and "What problems might this 
person have with intimacy and closeness?" Examples for autonomy are "What makes this person able to base decisions on his/her own judgement without relying on other people?" and "What problems might this person have with relying on others too

much?"1 Participants indicated, for each domain, the two questions to which they would choose to hear the friend's response. Positivity of feedback-seeking for each domain was indicated by the number of positive choices (of a possible two).

\section{Results}

\section{Attachment and Positivity of Selective Feedback-Seeking}

Because of missing data, final $N$ was 292. On average (Table 2), participants chose slightly more positive feedback than expected by chance. To test predictions, we regressed feedback-seeking positivity in each domain on attachment anxiety and avoidance (Table 3). We controlled for age, which correlated with feedback-seeking for autonomy and mastery $(r \mathrm{~s}=-.13$ and $-.12, p \mathrm{~s}<.05)$.

Avoidance was negatively associated with feedback-seeking positivity in all domains, but the coefficient was largest for relationships. Thus, consistent with Hypothesis 1, dismissing and fearful individuals chose relatively negative feedback, particularly about their close relationships.

Attachment anxiety was negatively associated with feedback-seeking positivity in the domains of mastery and autonomy. Thus, consistent with Hypothesis 2, secure and dismissing individuals chose more positive competence feedback than preoccupied and fearful individuals.

Finally, we decomposed the significant Anxiety $\times$ Avoidance interactions for relationships and mastery (Figure 1). We calculated simple slopes (Aiken \& West, 1991) one standard deviation above and below the mean on attachment anxiety and 
avoidance, illustrating patterns for each attachment style. For relationships, consistent with Hypothesis 1, secure individuals chose more positive feedback than those high in either anxiety or avoidance (preoccupied $\beta=-.17, p<.05$; dismissing $\beta=-.41, p<$ .001). Individuals high in avoidance chose negative feedback regardless of their anxiety level (fearful vs. dismissing; $\beta=.05, n s$ ), but those high in anxiety and low in avoidance chose more positive feedback than those high in both (preoccupied vs. fearful; $\beta=-.19$, $p<.05)$. For mastery, secure individuals chose more positive feedback than individuals with all other attachment patterns $(\beta s=-.21, p s<.01)$, who did not differ $(\beta s<.07, n s)$.

In sum, secure individuals sought the most positive feedback overall and highavoidant individuals the most negative, consistent with predictions and prior research (e.g., Brennan \& Morris, 1997). Preoccupied individuals sought some positive feedback about relationships: possibly, preoccupied individuals' desire for cues of approval and affection were stronger than fearful individuals', despite their shared low self-esteem. Consistent with Hypothesis 2, dismissing individuals sought positive feedback about autonomy, showing for the first time that they do not shun all input from others but seek positive feedback about self-relevant areas. However, this was not the case for mastery. The Role of Self-Esteem

We next examined whether attachment differences in positivity of selective feedback-seeking were accounted for by self-esteem (Hypothesis 3). Self-esteem correlated negatively with attachment anxiety and avoidance $(r \mathrm{~s}=-.47$ and $-.26, p \mathrm{~s}<$ $.001)$, but not with the Anxiety $\times$ Avoidance interaction $(r=.02, p=.72)$. Thus, patterns associated with the interaction could not be directly mediated (Baron \& Kenny, 1986). Simple regressions showed that self-esteem predicted positive feedback-seeking in the domains of mastery and autonomy (respective $\beta \mathrm{s}=.22$ and $.18, p \mathrm{~s}<.05$; other domains 
$\beta s<.07, p s>.15)$. Thus, we tested whether self-esteem mediated the significant effects of attachment anxiety on autonomy choice and avoidance on mastery choice.

Specifically, we examined whether attachment effects decreased when self-esteem was entered at Step 2 of a regression. We then used a bootstrapping procedure (Preacher \& Hayes, 2004) to formally test indirect effects by drawing 2,000 random samples from the data and computing the indirect effect in each.

For autonomy, although the effect of anxiety became non-significant in Step 2 ( $\beta$ reduced from $-.15, p<.01$, to $-.10, p=.14$ ), self-esteem only marginally predicted feedback-seeking positivity $(\beta=.12, p=.07$ ). The confidence interval for the indirect effect included zero $(95 \% \mathrm{CI}=-.103,+.005)$, indicating that the link between anxiety and autonomy choice was not mediated by self-esteem.

For mastery, self-esteem significantly predicted feedback-seeking positivity $(\beta=$ $.19, p<.01)$ and mediated the effect of avoidance ( $\beta$ reduced from $-.11, p=.07$, to -.07 , $p=.26)(99 \% \mathrm{CI}=-.082,-.002)$. However, the effect of Anxiety $\times$ Avoidance remained unchanged in Step $2(\beta=.11, p<.05)$. Simple slopes for the interaction, recalculated controlling for self-esteem, showed that differences between attachment styles were smaller than, but formed the same pattern as, depicted in Figure 1 (secure vs. dismissing $\beta=-.17, p<.05$, all other $\beta s<|.12|, n s)$. Thus, self-esteem levels partly, but not wholly, account for effects of attachment security on positive feedback-seeking about mastery. Effects of attachment in all other domains were independent of self-esteem.

\section{Discussion}

Study 1 examined whether people with different attachment orientations differently sought positive (vs. negative) hypothetical feedback about interpersonal and competence attributes. As expected, secure individuals showed most self-enhancing 
patterns by seeking the most positive feedback. High-avoidant individuals sought less positive feedback, especially about close relationships. Preoccupied individuals, however, did seek some positive feedback about close relationships: It seems that their motivation to seek cues of approval (due to high domain self-relevance) was stronger than their lack of self-enhancing ability (due to low self-esteem).

As predicted, dismissing individuals sought positive feedback about autonomy, demonstrating for the first time that they are motivated to self-enhance using feedback in personally relevant domains. However, like high-anxious individuals they did not seek positive feedback about mastery, suggesting that mastery feedback (from a friend) is less valued. The main distinction between the two domains concerns their implication for relationships: whereas mastery is purely intrapersonal, autonomy implies selfreliance as opposed to reliance on others. Thus, dismissing individuals may base selfworth more on independence than mastery. Importantly, although insecure people seek less positive feedback about mastery partly because of their lower self-esteem, the remaining findings were not explained by self-esteem levels. Thus, attachment patterns are influential in feedback contexts and are not simply a proxy for self-esteem.

Our results build on previous research by directly comparing feedback-seeking in interpersonal and competence domains for the first time. Prior attachment research had focused on feedback from romantic partners and had not systematically compared domains. Though correlational, our results suggest that insecurely attached people tend to seek negative feedback over positive, and this tendency differs across interpersonal and competence realms. Nevertheless, feedback in Study 1 was hypothetical and supposedly originated from a friend, who may more likely provide interpersonal than competence feedback. Our findings set the scene for studying different feedback- 
seeking patterns in a more ecologically valid context. This was the purpose of Study 2.

Study 2

The objectives of Study 2 were to replicate and extend Study 1 in a situation wherein participants believe they will actually receive feedback, and when feedback comes from a source uniquely relevant to either the interpersonal or competence realm. We also aimed to explore more textured feedback-seeking behaviours. To achieve these objectives, participants in Study 2 completed lab-based tasks relevant to interpersonal qualities and competence and were offered real feedback (though they never received it). Specifically, they were promised feedback about close relationships and social acceptance (ostensibly from students), and about mastery and autonomy (ostensibly from an official scoring system). Participants again chose from positive and negative options in each domain. As before (Table 1), we predicted that individuals high (vs. low) in either anxiety or avoidance would seek less positive interpersonal feedback (Hypothesis 1), and that individuals high in anxiety (but not those high in avoidance) would seek less positive competence feedback (Hypothesis 2). We again predicted that self-esteem would not explain these patterns (Hypothesis 3). To examine further individual differences, in Study 2 we also assessed openness to feedback and choice between interpersonal versus competence feedback. We next discuss these.

\section{Openness to Feedback}

Background. As well as preferring positive or negative feedback, one may be generally more open or averse to receiving feedback about oneself. One can begin conversations about oneself, welcome others' opinions, and undertake diagnostic tasks; or else divert conversation away from oneself and avoid diagnostic tasks. Aversion to feedback may hinder forming accurate and adaptive self-views (Trope, 1982). Hence, 
openness to (certain types of) feedback influences self-views differently than selective feedback-seeking does. Results regarding people's selective choices do not reveal their relative openness to feedback. For example, an individual who selects positive feedback might either be keen to hear positive things about herself, or averse to hearing negative things about herself, or equally keen for (or averse to) both types of feedback.

Attachment orientation may predict openness to interpersonal and competence feedback. High-avoidant individuals do not readily integrate new information into models of self and others (Green-Hennessy \& Reis, 1998; Mikulincer \& Arad, 1999), and defensively exclude relationship information from processing (Bowlby, 1980; Fraley, Garner, \& Shaver, 2000). This may foster low openness to interpersonal feedback. However, given that such defensiveness is specific to attachment-related information (Diamond \& Hicks, 2005; Mikulincer, Gillath, \& Shaver, 2002) and that avoidant people explore readily in non-relationship contexts (Green \& Campbell, 2000), they may be open to competence feedback. High-anxious individuals rely on others for self-worth (Park et al., 2004) and seek reassurance (Shaver et al., 2005), suggesting they may be very eager for interpersonal feedback. It is unclear whether fearful individuals will resemble the patterns linked to high avoidance or high anxiety, given that they possess both and rely on both interpersonal and agentic sources of self-worth (Park et al., 2004). Secure individuals are likely open to feedback, especially positive, because accurate self-knowledge is adaptive (Kumashiro \& Sedikides, 2005; Trope, 1982).

Research on attachment and openness to feedback is limited. Brennan and Bosson (1998) and Carnelley et al. (2007) asked participants about general experiences of feedback from romantic partners. Results suggested that secure individuals are most open, and dismissing individuals most averse, to interpersonal feedback. However, both 
studies relied on retrospection and did not compare positive to negative feedback. Rholes, Simpson, Tran, Martin, and Friedman (2007) offered participants in a stressful situation, computerised information about their romantic relationship characteristics and career. As participants felt more stressed, attachment anxiety predicted higher desire for negative (and lower desire for positive) relationship information, and avoidance predicted higher desire for career and negative relationship information. Thus, insecure (vs. secure) people may be more open to negative interpersonal feedback when stressed. Rholes et al. speculated that this could reflect a motive to reduce anxiety by confirming negative self-views (cf. Swann et al., 2003). Rholes et al.'s (2007) results support some of our predictions. However, the study did not separate positive and negative career information, and induced stress in participants. Given that people receive feedback in everyday life, when they may or may not be stressed, it is vital to examine everyday feedback-seeking patterns. The present study is the first to assess attachment differences in openness to positive and negative feedback directly (rather than retrospectively), in specific interpersonal and competence domains, without using a stress manipulation.

Hypotheses. Our predictions were again based on two factors. First, people are generally more open to feedback to the extent that a domain is self-relevant (vs. defensively excluded). Second, in self-relevant domains, people with higher self-esteem are more likely to self-enhance, and so will report higher openness to positive than negative feedback, compared to those with low self-esteem (see Table 1).

Interpersonal domains are highly self-relevant for preoccupied and fearful individuals, and fairly self-relevant for secure individuals. Preoccupied and fearful individuals should be open to all feedback because of their need for approval cues, whereas secure individuals should self-enhance (due to their high self-esteem) by being 
more open to positive than negative feedback. Dismissing individuals defensively exclude attachment-related information, so should be averse to all interpersonal feedback. Fearful individuals' openness may also be curtailed by their high avoidance. Thus, in the domains of relationships and acceptance, we expected avoidance to be negatively associated with openness to positive feedback, and anxiety positively associated with openness to negative feedback (Hypothesis 4).

Competence domains are highly self-relevant for dismissing and fearful individuals, and moderately relevant for secure individuals. Dismissing and secure individuals have high self-esteem, so should self-enhance by being more open to positive than negative feedback. Fearful individuals have low self-esteem, so may be relatively open to all competence feedback. Preoccupied individuals are less eager for feedback because competence is not self-relevant. Thus, in the domains of mastery and autonomy, we expected attachment anxiety to be negatively associated with openness to positive feedback, and both anxiety and avoidance to be positively associated with openness to negative feedback (i.e., fearful individuals most open) (Hypothesis 5).

\section{Interpersonal Versus Competence Feedback Choice}

Our final variable was choice of interpersonal versus competence feedback. For example, people can choose to spend time working alone or with others, or to talk about work or relationships. These choices impact opportunities to receive feedback, and thus develop self-views and skills, in each area. High-avoidant individuals base self-worth on competence, prefer information search to social interaction, and are more interested in career than relationship information when stressed (Mikulincer, 1997; Rholes et al., 2007). Conversely, high-anxious individuals are preoccupied with relationships, rely on others' opinions, and are keen for relationship information (Bartholomew \& Horowitz, 
1991; Rholes et al., 2007). Fearful individuals experience both motivations, whereas secure individuals do not depend on feedback to maintain self-views and should make balanced choices. Thus, we predicted that avoidance would positively predict choosing competence (over interpersonal) feedback, whereas attachment anxiety would positively predict choosing interpersonal (over competence) feedback (Hypothesis 6).

\section{The Role of Self-Esteem}

We again tested the mediating role of self-esteem for each feedback-seeking variable. Based on theory and Study 1 findings, we anticipated that most attachment differences in feedback-seeking would be independent of self-esteem levels.

\section{Method}

\section{Participants}

In total 112 undergraduates at a British University $\left(88 \%\right.$ female; $M_{\mathrm{AGE}}=20.11$, $S D=3.76$, range 18-40) participated for course credit and prize draw entry (two $£ 25$ prizes, approximately €33). The majority (83\%) were White-British. Half (49\%) were involved in a romantic relationship $\left(M_{\text {DURATION }}=24\right.$ months $)$.

\section{Procedure}

Phase 1. Participants accessed a website to complete attachment, self-esteem, and filler measures, presented in 12 varying orders.

Phase 2. Phase 2 took place one to four days after Phase 1, to eliminate priming effects. Two participants attended each laboratory session, in a room with two video cameras, and were told that the session would be video-recorded. Participants then completed two dyadic tasks with the researcher observing from another room.

The first (interpersonal) task comprised a structured 8-minute social interaction based around 10 neutral discussion topics (e.g., "Why did you choose to come to this 
university?"). We chose relatively neutral topics to avoid inducing relationship-relevant threat or stress (cf. Rholes et al., 2007). The second (competence) task comprised a 20minute problem-solving exercise. Participants were instructed to together build a bridge between two tables using newspaper and tape, which could support small weights. Instructions stated that the bridge would be scored using a standardised coding system, with points awarded for a range of aspects (e.g., efficient use of resources, planning).

After the tasks, participants were taken to separate rooms to read the cover story (see below) and complete the feedback-seeking measure. Finally, participants were verbally debriefed and informed they would not receive feedback.

\section{Measures: Phase 1}

We assessed romantic attachment using the ECR as in Study 1; anxiety $(\alpha=.93)$ and avoidance $(\alpha=.92)$ were again weakly correlated $(r=.16, p=.09)$. We assessed self-esteem with the SLCS-R as in Study $1(\alpha=.90)$.

\section{Measures: Phase 2}

Cover story. ${ }^{2}$ Written instructions, distributed after completing the dyadic tasks, stated that video data from the lab session would be coded for research purposes. To evaluate participants' interpersonal qualities, two undergraduates at another university would view the tape. To evaluate participants' individual competence and work skills, two experts would score the problem-solving task on its standardised scoring system. The raters would generate short summaries of participants' attributes in specific areas. Because previous participants had expressed interest in this information, each participant would be sent some of the summaries written about him or her. However, due to limited resources, participants would have to choose which feedback they would receive. In reality, videotapes were not scored and participants did not receive feedback. 
Feedback-seeking patterns. Participants read a list of specific feedback summaries available in the interpersonal set (close relationship qualities, likeabilityacceptance) and the competence set (daily mastery, autonomy-independence), presented in counterbalanced order. Each domain contained the six feedback items (three positive, three negative) used in Study 1. Participants rated the extent to which they wanted to receive each summary from 1 (not at all) to 9 (completely). Average openness was calculated for each domain and valence of feedback. Participants then selected, for each domain, two summaries that they wanted to receive. Positivity of feedback-seeking for each domain was indexed by number of positive choices (of a possible two). Finally, participants chose whether to receive the interpersonal or competence feedback set.

\section{Results}

\section{Positivity of Selective Feedback-Seeking}

Due to missing data, $N_{\mathrm{CHOICE}}=109 .{ }^{3}$ Table 2 shows that, unlike Study 1 , participants chose slightly more negative feedback than expected by chance.

Regressions showed, as in Study 1, a consistent (though not always significant) negative association between avoidance and feedback-seeking positivity across domains (Table 3). There was a negative association between anxiety and feedback-seeking positivity in the domain of relationships. This differed from Study 1, in which preoccupied participants sought some positive relationship feedback. Finally, a marginal Anxiety $\times$ Avoidance interaction emerged in the domain of mastery. This indicated that, as in Study 1 , secure individuals chose more positive mastery feedback than individuals with any type of insecurity $(\beta s<-.30, p s<.05)$, who did not differ $(\beta s<I .11 \mid, n s)$.

This pattern of results supports the prediction that secure people seek the most positive feedback in interpersonal domains (Hypothesis 1). However, unlike Study 1 
there was no evidence that dismissing people self-enhance by seeking positive feedback about competence (Hypothesis 2). Instead, high-avoidant individuals' lack of positive feedback-seeking emerged across all domains. We defer consideration of possible reasons for this until the Discussion.

\section{Openness to Feedback}

We excluded data from four multivariate outliers, $\chi_{\text {critical }}^{2}(10, \alpha=.001)=29.6$, which altered some results. Due to missing data, $N_{\text {OPENNESS }}=105$. Table 2 shows that participants were more open to positive than negative feedback in interpersonal domains, but vice versa in competence domains. To test hypotheses, we regressed openness to each domain and valence of feedback on attachment dimensions (Table 4).

Across domains, participants with high, versus low, avoidance tended to be more open to negative feedback (significant in every domain except acceptance) but not positive feedback. This pattern suggested that high-avoidant participants may have chosen to receive negative feedback (Table 3 ) because they explicitly desired it—not because they did not want positive feedback. Thus, as found by Rholes et al. (2007) for relationship information, high-avoidant individuals desired negative feedback more than did low-avoidant individuals.

Attachment anxiety was marginally positively associated with openness to negative feedback about close relationships (Table 4). Thus, supporting Hypothesis 4, high-anxious participants were slightly more open to negative feedback about relationships but not about other domains. This result is consistent with their choosing negative over positive feedback (above) and with Rholes et al.'s (2007) finding that attachment anxiety predicted interest in negative relationship information under stress. However, attachment anxiety did not significantly predict openness to competence 
feedback, failing to support Hypothesis 5.

The Anxiety $\times$ Avoidance interaction marginally predicted openness to both positive and negative acceptance feedback (Table 3), and the coefficient was significant when positive and negative feedback were averaged, $\beta=-.20, p<.05$. Simple slopes (Figure 2) showed that secure individuals were less open to feedback about acceptance than all insecure individuals $(\beta \mathrm{s} \approx .30, p \mathrm{~s}<.05)$, who did not differ $(\beta \mathrm{s}<1.10 \mathrm{l}, n s)$. This pattern is consistent with Hypothesis 4, which predicted that high-anxious individuals desire cues of approval from others. Surprisingly, this desire for acceptance feedback emerged not only for high-anxious participants but also for dismissing participants.

In sum, compared to secure people, (a) high-avoidant people were more open to negative feedback, (b) high-anxious people were more open to negative feedback about close relationships, and (c) people with any insecurity were more open to feedback about their social acceptance. Thus, rather than protecting themselves from negative information, insecure participants welcomed it. High-avoidant individuals' desire for negative feedback emerged in competence as well as interpersonal domains: they did not self-protect in the self-relevant areas of mastery or autonomy. Results support the prediction that insecure people are more open to negative than positive feedback and suggest mechanisms underlying their lack of positive feedback choices in both studies. Interpersonal Versus Competence Feedback Choice

Overall, $64.3 \%$ of participants chose interpersonal over competence feedback, $\chi_{(1, N=112)}^{2}=9.14, p<.01$. To assess the role of attachment, we conducted a logistic regression predicting the binary outcome of domain choice (Table 5). Consistent with Hypothesis 6, high-anxious participants were more likely than low-anxious participants to choose interpersonal feedback, supporting their eagerness for acceptance-relevant 
information. The odds ratio shows that a one-unit increase in attachment anxiety rendered choosing interpersonal feedback 56\% more likely. Contrary to Hypothesis 6 , avoidance was not significantly associated with this choice, although the coefficient was in the predicted direction. This implies that fearful individuals (who are high in anxiety and avoidance) are more motivated to seek feedback about their interpersonal sources of self-worth than their competence sources of self-worth (cf. Park et al., 2004).

Dismissing individuals' surprising failure to pursue competence over interpersonal feedback echoes their lack of positive competence feedback-seeking (Table 3).

The Role of Self-Esteem

We examined whether self-esteem mediated attachment differences in feedbackseeking as in Study 1. Self-esteem correlated negatively with attachment anxiety and avoidance $(r \mathrm{~s}=-.55$ and $-.25, p \mathrm{~s}<.01)$, but not Anxiety $\times$ Avoidance $(r=.14, p=.15)$. For positivity of selective feedback-seeking, self-esteem predicted feedback-seeking for mastery and autonomy $(\beta \mathrm{s}>.19, \mathrm{ps}<.05)$. For openness to feedback, self-esteem predicted only openness to negative mastery feedback $(\beta=-.22, p<.05)$. However, adding self-esteem at Step 2 did not predict any of these feedback-seeking criteria or reduce effects of attachment. In sum, secure individuals did not desire, or seek, positive feedback purely because of their higher self-esteem. Likewise, self-esteem was not associated with preferring either interpersonal or competence feedback (Table 5).

\section{Results Summary}

Study 2 extended Study 1 by assessing several aspects of feedback-seeking when participants expected to receive feedback from domain-relevant sources (i.e., interpersonal feedback from peers; competence feedback from objective experts). Results of Study 2 suggest that, compared to secure individuals, high-avoidant 
individuals seek more negative feedback across most domains. Moreover, this may occur because they are more open than secure individuals to negative feedback (not less open to positive feedback). High-anxious individuals are open to negative feedback and seek less positive feedback about close relationships, but prefer interpersonal over competence feedback. Finally, individuals with any type of insecurity were more open to feedback about social acceptance than secure individuals. This finding was predicted for high-anxious individuals, who rely on social sources for self-worth, but also emerged for dismissing individuals. None of these effects was explained by self-esteem.

\section{General Discussion}

Our research examined the ways in which adult attachment orientation relates to feedback-seeking patterns in interpersonal and competence areas of life. Two studiesone considering hypothetical feedback from a friend, one offering real feedback from domain-relevant sources—-showed meaningful links between attachment and feedbackseeking. Our findings are consistent with theoretical predictions that attachment security (vs. insecurity) enables a person to self-enhance by seeking positive over negative feedback in personally important areas of life. Study 2 suggested that this tendency may be partly underlain by avoiding negative feedback. Moreover, these patterns were not explained by secure individuals' higher self-esteem. In contrast, insecure attachment strategies are characterised by less adaptive feedback-seeking tendencies.

Consistently across both studies, individuals with high (vs. low) avoidance generally chose negative feedback over positive. Study 2 suggested that this reflects high-avoidant people's relatively greater openness to negative feedback. Possibly, secure people self-protect, by avoiding negative feedback, more than insecure people. Consistent with this interpretation, after failure, people with high self-esteem suppress 
their weaknesses (Dodgson \& Wood, 1998) and are disinclined to persist at a task (Baumeister \& Tice, 1985): They avoid receiving and processing negative self-relevant information. Alternatively, insecure individuals may possess a desire for negative information, reflecting a motive to self-improve (Taylor et al., 1995), a motive to confirm negative views of self and others (Swann et al., 2003), or a tendency to easily process information consistent with their negative schemas (Alloy \& Lipman, 1992). Whatever the motive behind this negative feedback-seeking, insecure people react negatively to negative feedback (Collins et al., 2006; Carnelley et al., 2007; Hepper \& Carnelley, 2008); thus, in the long-term their behaviour results in lower self-esteem.

High-avoidant individuals theoretically derive self-worth from feeling masterful and independent, to defend them from rejection by excluding attachment information from processing. In interpersonal domains, these people may seek negative feedback to preserve the belief that others are unreliable. This replicates their retrospective reports of feedback from romantic partners (Brennan \& Bosson, 1998). It is also consistent with Rowe's (2003) finding that people primed with an avoidant attachment style showed automatic behavioural avoidance of positive (and approach to negative) attachment stimuli. However, our results suggest that high-avoidant people seek negative feedback in the competence realm as well. In Study 1, when feedback came from a friend, dismissing individuals did seek positive feedback about autonomy. But in Study 2, when feedback came from a non-social source, they did not. Nor did they pursue competence over interpersonal feedback when offered the choice. Possibly, dismissing adults are most motivated to self-enhance about autonomy by soliciting feedback from another person-ironically refuting their claimed self-sufficiency and independent selfworth (Park et al., 2004). Research could test this notion by comparing attitudes to 
autonomy feedback from social versus non-social sources. Daily mastery may be less self-relevant for dismissing adults: Whether offered interpersonal or objective feedback about this purely intrapersonal domain, they did not exhibit self-enhancing behaviour.

High-anxious individuals theoretically derive self-worth from others' acceptance and affection, because they cannot regulate self-esteem internally. We found that in these areas they did desire feedback, but only inconsistently self-enhanced. In support of their desire for self-relevant feedback, high-anxious participants in Study 2 were more open to feedback about close relationships and social acceptance (the former only when negative). Moreover, high-anxious individuals chose interpersonal over competence feedback, whereas low-anxious individuals were balanced in their choice. Regarding self-enhancing patterns, preoccupied participants in Study 1 chose some positive feedback about close relationships, suggesting that their low self-esteem did not entirely prevent them from seeking positivity. In Study 2, however, they chose relatively negative relationship feedback. High-anxious individuals might be more likely to selfenhance by seeking positive feedback from a friend, or might be more motivated to selfimprove by seeking negative feedback from a stranger. Further research is needed to tease apart the motives underlying secure and insecure feedback-seeking patterns.

High-anxious people's feedback-seeking behaviours may play a central role in maintaining their low self-esteem and negative self-views (cf. Mikulincer, 1995). They choose to pursue interpersonal feedback, and then seek out and welcome negative information within those scenarios. After receiving negative feedback, high-anxious people are known to feel worse about themselves, experience spreading negative affect, and alter their self-views (Carnelley et al., 2007; Collins et al., 2006). Our findings also echo the link between anxious attachment and excessive reassurance-seeking, known to 
elicit negative feedback and contribute to relationship conflict and depression (Brennan \& Carnelley, 1999; Joiner, Metalsky, Katz, \& Beach, 1999; Shaver et al., 2005).

Our findings suggest that negative feedback-seeking manifests differently depending on one's constellation of anxiety and avoidance. For example, a dismissing individual is unlikely to instigate conversations about relationships, but during such conversations he or she may elicit negative feedback (e.g., by asserting his/her independence). In contrast, a preoccupied individual will eagerly initiate conversations about relationships, but may elicit negative feedback by asking for reassurance in a maladaptive way (e.g., "What's wrong with me?"). Overall, these patterns echo the vulnerability factors that link attachment insecurity to poor intrapersonal and interpersonal functioning (cf. Feeney, 1999; Zuroff \& Fitzpatrick, 1995). That is, avoidant people create interpersonal negativity by focusing on independence and seeking negative relational feedback, whereas anxious people inadvertently seek negative feedback from others despite depending on them for self-regulation.

Fearful individuals may display the most maladaptive feedback-seeking behaviour. Overall, our results suggest that fearful people desire and choose negative feedback, especially about relationships, and pursue interpersonal over competence feedback. Thus, as well as relying on both social and competence sources of self-worth (Park et al., 2004), they are highly vulnerable to receiving negative feedback. Some authors have suggested that fearful attachment reflects unsuccessful deactivation of the attachment system (Simpson \& Rholes, 2002). This implies that fearful adults attempt to draw self-worth from exploration and independence but retain an underlying need for love and approval. Our findings identify a possible consequence of this vulnerability: negative feedback-seeking that maintains negative self-views. 
Interestingly, our results hint that dismissing people may not be as immune to interpersonal cues as they claim (Park et al., 2004). In Study 2, they were eager for social acceptance feedback. Recent evidence supports this finding. Carvallo and Gabriel (2006) reported that bogus positive feedback about social acceptance raised state selfesteem for dismissing, but not secure individuals, again implying that such feedback is self-relevant. On a perceptual level, three studies found that dismissing individuals are vigilant to negative facial expressions (Magai, Hunziker, Mesias, \& Culver, 2000; Niedenthal, Brauer, Robin, \& Inns-Ker, 2002) and social and emotional pictures (Maier et al., 2005). Thus, their defences may belie a fixation with attachment concerns. The present result implies another arena in which dismissing people's defences may falter.

We acknowledge that our research was correlational, limiting causal interpretation. Future research might address causality by priming attachment security or insecurity and measuring subsequent feedback-seeking. Attachment orientation and feedback-seeking patterns likely exert mutual influence, creating virtuous or vicious cycles that maintain positive or negative self-views. In conclusion, our findings highlight that people are active participants in their feedback destinies. In idiosyncratic ways, people with different types of attachment insecurity create feedback environments that maintain their negative views of self and others and their maladaptive relationship and personal functioning. Future research should focus on these idiosyncrasies to enrich understanding of individual differences in attachment and self-view maintenance. 


\section{References}

Aiken, L. S., \& West, S. G. (1991). Multiple regression: Testing and interpreting interactions. Thousand Oaks: Sage.

Ainsworth, M. S., Blehar, M. C., Waters, E., \& Wall, S. (1978). Patterns of attachment: A psychological study of the Strange Situation. Hillsdale, NJ: Erlbaum.

Alloy, L. B., \& Lipman, A. J. (1992). Depression and selection of positive and negative social feedback: Motivated preference or cognitive balance? Journal of Abnormal Psychology, 101, 310-313.

Baron, R. M., \& Kenny, D. A. (1986). The moderator-mediator variable distinction in social psychological research: Conceptual, strategic, and statistical considerations. Journal of Personality and Social Psychology, 51, 1173-1182.

Bartholomew, K., \& Horowitz, L. (1991). Attachment styles among young adults: A test of a four-category model. Journal of Personality and Social Psychology, 61, 226-244.

Baumeister, R. F., \& Tice, D. M. (1985). Self-esteem and responses to success and failure: Subsequent performance and intrinsic motivation. Journal of Personality, 53, 450-467.

Bollen, K. A., \& Stine, R. (1990). Direct and indirect effects: Classical and bootstrap estimates of variability. Sociological Methodology, 20, 115-140.

Bowlby, J. (1969). Attachment and loss. Vol. 1: Attachment. London: Hogarth.

Bowlby, J. (1973). Attachment and loss. Vol. 2: Separation. New York: Basic Books.

Bowlby, J. (1980). Attachment and loss. Vol. 3: Loss, sadness and depression. London: Hogarth.

Brennan, K. A., \& Bosson, J. K. (1998). Attachment-style differences in attitudes 
toward and reactions to feedback from romantic partners: An exploration of the relational bases of self-esteem. Personality and Social Psychology Bulletin, 24, 699-714.

Brennan, K. A., \& Carnelley, K. B. (1999). Using meaning to mend holes in the nomological net of excessive reassurance-seeking and depression. Psychological Inquiry, 10, 282-285.

Brennan, K. A., Clark, C. L., \& Shaver, P. R. (1998). Self-report measurement of adult romantic attachment: An integrative overview. In J. A. Simpson \& W. S. Rholes (Eds.), Attachment theory and close relationships (pp. 46-76). New York: Guilford.

Brennan, K. A., \& Morris, K. A. (1997). Attachment styles, self-esteem, and patterns of seeking feedback from romantic partners. Personality and Social Psychology Bulletin, 23, 23-31.

Campbell, L., Simpson, J. A., Boldry, J., \& Kashy, D. A. (2005). Perceptions of conflict and support in romantic relationships: The role of attachment anxiety. Journal of Personality and Social Psychology, 88, 510-531.

Carnelley, K. B., Israel, S., \& Brennan, K. A. (2007). The role of attachment in influencing reactions to manipulated feedback from romantic partners. European Journal of Social Psychology, 37, 968-986.

Carvallo, M., \& Gabriel, S. (2006). No man is an island: The need to belong and dismissing avoidant attachment style. Personality and Social Psychology Bulletin, 32, 697-709.

Cassidy, J., Ziv, Y., Mehta, T. G., \& Feeney, B. C. (2003). Feedback seeking in children and adolescents: Associations with self-perceptions, attachment representations, 
and depression. Child Development, 74, 612-628.

Collins N. L., Ford, M. B., Guichard, A. C., \& Allard, L. M. (2006). Working models of attachment and attribution processes in intimate relationships. Personality and Social Psychology Bulletin, 32, 201-219.

Crocker, J., \& Wolfe, C. T. (2001). Contingencies of self- worth. Psychological Review, $10,593-623$.

Diamond, L. M., \& Hicks, A. M. (2005). Attachment style, current relationship security, and negative emotions: The mediating role of physiological regulation. Journal of Social and Personal Relationships, 22, 499-518.

Dodgson, P. G., \& Wood, J. V. (1998). Self-esteem and the cognitive accessibility of strengths and weaknesses after failure. Journal of Personality and Social Psychology, 75, 178-197.

Feeney, J. A. (1999). Issues of closeness and distance in dating relationships: Effects of sex and attachment style. Journal of Social and Personal Relationships, 16, 571590.

Foster, J. D., Kernis, M. H., \& Goldman, B. M. (2007). Linking adult attachment to self-esteem stability. Self and Identity, 6, 64-73.

Fraley, R. C., Davis, K. E., \& Shaver, P. R. (1998). Dismissing-avoidance and the defensive organization of emotion, cognition, and behavior. In J. A. Simpson \& W. S. Rholes (Eds.), Attachment theory and close relationships (pp. 249-279). New York: Guilford Press.

Fraley, R. C., Garner, J. P., \& Shaver, P. R. (2000). Adult attachment and the defensive regulation of attention and memory: Examining the role of preemptive and postemptive defensive processes. Journal of Personality and Social Psychology, 
79, 816-826.

Fraley, R. C., \& Waller, N. G. (1998). Adult attachment patterns: A test of the typological model. In J. A. Simpson \& W. S. Rholes (Eds.), Attachment theory and close relationships (pp. 77-114). New York: Guilford.

Green, J. D., \& Campbell, W. K. (2000). Attachment and exploration in adults: Chronic and contextual accessibility. Personality and Social Psychology Bulletin, 26, $452-461$.

Green-Hennessy, S., \& Reis, H. T. (1998). Openness in processing social information among attachment types. Personal Relationships, 5, 449-466.

Hardy, G. E., \& Barkham, M. (1994). The relationship between interpersonal attachment styles and work difficulties. Human Relations, 47, 263-281.

Hazan, C., \& Shaver, P. R. (1990). Love and work: An attachment-theoretical perspective. Journal of Personality and Social Psychology, 59, 270-280.

Hepper. E. G., \& Carnelley, K. B. (2008, July). Adult attachment and lability of daily self-esteem and relationship evaluations. Paper presented at the International Association of Relationship Research Conference, Providence, RI.

Joiner, T. E., Metalsky, G. I., Katz, J., \& Beach, S. R. H. (1999). Depression and excessive reassurance-seeking. Psychological Inquiry, 10, 269-278.

Kumashiro, M., \& Sedikides, C. (2005). Taking on board liability-focused information: Close positive relationships as a self-bolstering resource. Psychological Science, $16,732-739$.

Magai, C., Hunziker, J., Mesias, W., \& Culver, L. C. (2000). Adult attachment styles and emotional biases. International Journal of Behavioral Development, 24, 301-309. 
Maier, M. A., Bernier, A., Pekrun, R., Zimmerman, P., Strasser, K., \& Grossman, K. E. (2005). Attachment state of mind and perceptual processing of emotional stimuli. Attachment and Human Development, 7, 67-81.

Mikulincer, M. (1995). Attachment style and the mental representation of the self. Journal of Personality and Social Psychology, 69, 1203-1215.

Mikulincer, M. (1997). Adult attachment style and information processing: Individual differences in curiosity and cognitive closure. Journal of Personality and Social Psychology, 72, 1217-1230.

Mikulincer, M., \& Arad, D. (1999). Attachment working models and cognitive openness in close relationships: A test of chronic and temporary accessibility effects. Journal of Personality and Social Psychology, 77, 710-725.

Mikulincer, M., Dolev, T., \& Shaver, P. R. (2004). Attachment-related strategies during thought-suppression: Ironic rebounds and vulnerable self-representations. Journal of Personality and Social Psychology, 87, 940-956.

Mikulincer, M., \& Florian, V. (1998). The relationship between adult attachment styles and emotional and cognitive reactions to stressful events. In J. A. Simpson \& W. S. Rholes (Eds.), Attachment theory and close relationships (pp. 143-165). New York: Guilford.

Mikulincer, M., Gillath, O., \& Shaver, P. R. (2002). Activation of the attachment system in adulthood: Threat-related primes increase the accessibility of mental representations of attachment figures. Journal of Personality and Social Psychology, 83, 881-895.

Mikulincer, M., \& Shaver, P. R. (2004). Security-based self-representations in adulthood: Contents and processes. In W. S. Rholes \& J. A. Simpson (Eds.), 
Adult attachment: Theory, research, and clinical implications (pp. 159-195). New York: Guilford Press.

Mikulincer, M., Shaver, P. R., \& Pereg, D. (2003). Attachment theory and affect regulation: The dynamics, development, and cognitive consequences of attachment-related strategies. Motivation and Emotion, 27, 77-102.

Niedenthal, P. M., Brauer, M., Robin, L., \& Innes-Ker, A. H. (2002). Adult attachment and the perception of facial expression of emotion. Journal of Personality and Social Psychology, 82, 419-433.

Park, L. E., Crocker, J., \& Mickelson, K. D. (2004). Attachment styles and contingencies of self-worth. Personality and Social Psychology Bulletin, 30, $1243-1254$.

Preacher, K. J., \& Hayes, A. F. (2004). SPSS and SAS procedures for estimating indirect effects in simple mediation models. Behavior Research Methods, Instruments, and Computers, 36, 717-731.

Rholes, W. S., Simpson, J. A., Tran, S., Martin, A. M., \& Friedman, M. (2007). Attachment and information seeking in romantic relationships. Personality and Social Psychology Bulletin, 33, 422-438.

Rowe, A. C. (2003, June). General and relationship-specific attachment styles and their influence on automatically elicited behavioural responses to attachmentrelevant stimuli. Poster presented at the Compassionate Love IARR meeting in Bloomington-Normal, Chicago, USA.

Sedikides, C., \& Gregg, A. P. (2003). Portraits of the self. In M. A. Hogg \& J. Cooper (Eds.), Sage handbook of social psychology (pp. 110-138). London: Sage.

Sedikides, C., \& Strube, M. J. (1997). Self-evaluation: To thine own self be good, to 
thine own self be sure, to thine own self be true, and to thine own self be better. Advances in Experimental Social Psychology, 29, 209-269.

Seta, J. J., Donaldson, S., \& Seta, C. E. (1999). Self-relevance as a moderator of selfenhancement and self-verification. Journal of Research in Personality, 33, 442462.

Shaver, P. R., Schachner, D. A., \& Mikulincer, M. (2005). Attachment style, excessive reassurance seeking, relationship processes, and depression. Personality and Social Psychology Bulletin, 31, 343-359.

Shaver, P. R., \& Mikulincer, M. (2004). What do self-report attachment measures assess? In W. S. Rholes \& J. A. Simpson (Eds.), Adult attachment: Theory, research, and clinical implications (pp. 17-54). New York: Guilford.

Simpson, J. A., \& Rholes, W. S. (2002). Fearful-avoidance, disorganization, and multiple working models: Some directions for future theory and research. Attachment and Human Development, 4, 223-229.

Swann, W. B., Jr., Rentfrow, P. J., \& Guinn, J. (2003). Self-verification: The search for coherence. In M. Leary and J. Tangney, Handbook of self and identity (pp. 367383). New York: Guilford.

Swann, W. B., Jr., Wenzlaff, R. M., Krull, D. S., \& Pelham, B. W. (1992). Allure of negative feedback: Self-verification strivings among depressed persons. Journal of Abnormal Psychology, 101, 293-306.

Tafarodi, R. W., \& Swann, W. B., Jr. (2001). Two-dimensional self-esteem: Theory and measurement. Personality and Individual Differences, 31, 651-673.

Taylor, S. E., Neter, E., \& Wayment, H. A. (1995). Self-evaluation processes. Personality and Social Psychology Bulletin, 21, 1278-1287. 
Tice, D. M. (1991). Esteem protection or enhancement? Self-handicapping motives and attributions differ by trait self-esteem. Journal of Personality and Social Psychology, 60, 711-725.

Trope, Y. (1982). Self-assessment and task performance. Journal of Experimental Social Psychology, 18, 201-215.

Wei, M., Mallinckrodt, B., Russell, D. W., \& Abraham, W. T. (2004). Maladaptive perfectionism as a mediator and moderator between adult attachment and depressive mood. Journal of Counseling Psychology, 51, 201-212.

Zuroff, D. C., \& Fitzpatrick, D. K. (1995). Depressive personality styles: Implications for adult attachment. Personality and Individual Differences, 18, 253-365. 


\section{Author Note}

Erica G. Hepper and Katherine B. Carnelley, School of Psychology, University of Southampton, United Kingdom.

This research formed part of the first author's doctoral dissertation, and was supported by an Economic and Social Research Council studentship. The authors would like to thank Elle Boag, Angela Devereux, Catherine Revolta, Laura Sutcliffe, and Tamsin Thorne for assistance with data collection.

Correspondence concerning this article should be addressed to Erica Hepper, Ph.D., School of Psychology, University of Southampton, Southampton, SO17 1BJ, United Kingdom. Telephone: +44 (0) 238059 4584; fax: +44 (0) 238059 3328; email: E.Hepper@soton.ac.uk. 


\section{Footnotes}

${ }^{1}$ The first author and two assistants designed a pool of positive and negative questions in each domain. Questions were selected/refined based on 29 undergraduates' ratings of (a) valence of each question's likely response, and (b) the extent to which it assessed each domain. The final questions were distinctly positive or negative, and tapped the intended domain but not other domains.

${ }^{2}$ After completing dependent measures, participants completed a funnel debriefing questionnaire, with the key question: "Was there anything about this study that you did not believe?" assessing suspicion regarding feedback. Eight participants expressed significant doubt about receiving feedback; however, removing their data did not change any results except for reducing power and corresponding significance values. Therefore, we kept them in the sample.

${ }^{3}$ Supplementary analyses confirmed that age had no effects on any feedbackseeking variables in Study 2. We also sought to confirm that feedback-seeking positivity and openness to feedback were distinct variables. Positivity of selective feedbackseeking correlated weakly with openness to positive feedback (average within-domain $r$ $=.07$, range .02 to .23 ) and moderately with openness to negative feedback (average $r=$ -.48 , range -.39 to -.55$)$. Thus, the different feedback-seeking variables are not redundant (i.e., share less than $30 \%$ of variance) and warrant separate examination. 
Table 1

Summary of Predictions for Feedback-Seeking Patterns by Attachment Style Based on Combined Effects of Domain Relevance and Self-Esteem

\begin{tabular}{|c|c|c|c|c|c|}
\hline \multirow[b]{2}{*}{ Attachment Style } & \multicolumn{2}{|c|}{ Individual Differences } & \multicolumn{3}{|c|}{ Predicted Feedback-Seeking Patterns } \\
\hline & $\begin{array}{c}\text { Domain } \\
\text { Relevance }\end{array}$ & $\begin{array}{c}\text { Self- } \\
\text { Esteem }\end{array}$ & $\begin{array}{l}\text { Selective } \\
\text { Choices }\end{array}$ & $\begin{array}{l}\text { Openness } \\
\text { (Positive) }\end{array}$ & $\begin{array}{l}\text { Openness } \\
\text { (Negative) }\end{array}$ \\
\hline \multicolumn{6}{|c|}{ Interpersonal Feedback } \\
\hline Secure & Medium & High & Positive & High & Moderate \\
\hline Dismissing & Low & - & Negative & Low & Low \\
\hline Preoccupied & High & Low & Negative & High & High \\
\hline Fearful & High & Low & Negative & Moderate & Moderate \\
\hline \multicolumn{6}{|c|}{ Competence Feedback } \\
\hline Secure & Medium & High & Positive & High & Moderate \\
\hline Dismissing & High & High & Positive & High & Moderate \\
\hline Preoccupied & Low & - & Negative & Low & Low \\
\hline Fearful & High & Low & Negative & High & High \\
\hline
\end{tabular}

Note. If domain relevance is low, we expect neutral or negative feedback-seeking choices and low openness to feedback (regardless of self-esteem level, indicated by a dash through the self-esteem column). If domain relevance is medium or high, we expect increased openness to feedback, and we expect positivity of selective feedbackseeking (i.e., selective choices) and relative openness to positive (vs. negative) feedback to vary with self-esteem level. 
Table 2

Means for Feedback-Seeking Variables by Type of Feedback

\begin{tabular}{|c|c|c|c|c|c|c|}
\hline \multirow{3}{*}{ Domain } & \multicolumn{4}{|c|}{ Positivity of Feedback-Seeking } & \multirow{2}{*}{\multicolumn{2}{|c|}{$\begin{array}{c}\text { Openness to Feedback } \\
\text { Study } 2\end{array}$}} \\
\hline & \multicolumn{2}{|c|}{ Study 1} & \multicolumn{2}{|c|}{ Study 2} & & \\
\hline & $\mathrm{M}$ & $S D$ & $\mathrm{M}$ & $S D$ & Positive & Negative \\
\hline Relationships & 1.19 & 0.75 & 0.96 & 0.77 & $6.48_{b}$ & $6.21_{\mathrm{b}}$ \\
\hline Acceptance & 1.16 & 0.78 & 0.84 & 0.66 & $6.79_{a}$ & $6.40_{\mathrm{ab}}$ \\
\hline Mastery & 1.10 & 0.78 & 0.81 & 0.71 & $6.40_{\mathrm{b}}$ & $6.73_{\mathrm{a}}$ \\
\hline Autonomy & 1.15 & 0.79 & 0.82 & 0.70 & $6.17_{\mathrm{b}}$ & $6.47_{\mathrm{ab}}$ \\
\hline Total & 1.15 & 0.57 & 0.86 & 0.51 & 6.46 & 6.45 \\
\hline
\end{tabular}

Notes. Study 1: $n=292$. Study 2: $n=109$ for choice and $n=105$ for openness.

Choice scores represent number of positive choices (out of 2). In Study 1, mean choice in all domains was significantly more positive than expected by chance (i.e., 1); $t \mathrm{~s}>2.15, p \mathrm{~s}<.05$. In Study 2, mean choice for acceptance, mastery, and autonomy were more negative than expected by chance; $t \mathrm{~s}<-2.49, p \mathrm{~s}<.05$ (relationships $t=-$ $0.50, n s)$. In both studies, mean choice did not differ significantly across domains.

Openness to feedback in Study 2 was assessed on a scale from 1-9. Standard deviations ranged from 1.39 (positive mastery) to 2.02 (negative relationships). Positive and negative feedback differed significantly for acceptance, mastery, and autonomy ( $p$ s $<.05)$. Means within the same column that do not share a subscript differ at $p<.05$ in planned pairwise comparisons with Bonferroni adjustment. 
Table 3

Associations between Attachment Dimensions and Positivity of Selective Feedback-

Seeking (Regression Analyses)

\begin{tabular}{|c|c|c|c|c|c|c|}
\hline \multirow{2}{*}{$\begin{array}{l}\text { Feedback } \\
\text { Domain }\end{array}$} & \multicolumn{3}{|c|}{ Step 1} & \multicolumn{2}{|c|}{ Step 2} & \multirow{2}{*}{$\begin{array}{c}\text { Total } \\
R^{2}\end{array}$} \\
\hline & Anxiety & Avoid & $F_{\text {change }}$ & Anx*Avo & $F_{\text {change }}$ & \\
\hline \multicolumn{7}{|c|}{ Study 1} \\
\hline Relationships & -.07 & $-.29^{* * * *}$ & $11.67^{* * *}$ & $-.12^{*}$ & $4.61^{*}$ & $.12^{* * *}$ \\
\hline Acceptance & -.00 & -.05 & $<1$ & .05 & $<1$ & .00 \\
\hline Mastery & $-.11^{\dagger}$ & $-.11^{*}$ & $4.22^{* *}$ & $.11^{*}$ & $3.87^{*}$ & $.06^{* *}$ \\
\hline Autonomy & $-.15^{* *}$ & -.06 & $4.63^{* *}$ & .04 & $<1$ & $.05^{* *}$ \\
\hline \multicolumn{7}{|c|}{ Study 2} \\
\hline Relationships & $-.22^{*}$ & $-.22^{*}$ & $6.67^{* *}$ & .14 & 2.37 & $.13^{* *}$ \\
\hline Acceptance & -.09 & -.15 & 1.85 & .12 & 1.71 & .05 \\
\hline Mastery & -.12 & $-.17^{\dagger}$ & $2.73^{\dagger}$ & $.16^{\dagger}$ & $2.79^{\dagger}$ & $.07^{*}$ \\
\hline Autonomy & -.01 & $-.22^{*}$ & $2.88^{\dagger}$ & .03 & $<1$ & .05 \\
\hline
\end{tabular}

Notes. Study 1: $N=292$; Study 2: $N=109$. Anx = Anxiety; Avo = Avoidance. In Study 1, analyses controlled for age. Coefficients for Anxiety and Avoidance did not alter in Step 2, so are omitted for brevity.

${ }^{\dagger} p<.10$. $^{*} p<.05 .{ }^{* *} p<.01 .^{* * *} p<.001$. 
Table 4

Study 2: Associations between Attachment Dimensions and Openness to Feedback

(Regression Analyses)

\begin{tabular}{lcccccc}
\hline \multirow{2}{*}{ Feedback Type } & \multicolumn{3}{c}{ Step 1 } & \multicolumn{2}{c}{ Step 2 } & Total \\
& Anx & Avo & $F_{\text {change }}$ & Anx*Avo & $F_{\text {change }}$ & $R^{2}$ \\
\hline Positive & & & & & & \\
Relationships & -.06 & -.05 & $<1$ & -.03 & $<1$ & .01 \\
Acceptance & .15 & .07 & 1.76 & $-.18^{\dagger}$ & $3.70^{\dagger}$ & $.07^{\dagger}$ \\
Mastery & .04 & -.04 & $<1$ & .03 & $<1$ & .00 \\
Autonomy & .03 & -.03 & $<1$ & .12 & 1.52 & .02 \\
Negative & & & & & & \\
Relationships & $.17^{\dagger}$ & $.21^{*}$ & $5.10^{* *}$ & .12 & 1.60 & $.10^{*}$ \\
Acceptance & .14 & .14 & $2.66^{\dagger}$ & $-.17^{\dagger}$ & $3.21^{\dagger}$ & $.08^{*}$ \\
Mastery & .09 & $.22^{*}$ & $3.59^{*}$ & -.07 & $<1$ & $.07^{\dagger}$ \\
Autonomy & .09 & $.21^{*}$ & $3.27^{*}$ & .06 & $<1$ & $.06^{\dagger}$ \\
\hline
\end{tabular}

Notes. $N=109$. Anx $=$ Anxiety; Avo $=$ Avoidance. Coefficients for anxiety and avoidance did not alter in Step 2 so are omitted for brevity.

${ }^{\dagger} p<.10, * p<.05, * * p<.01, * * * p<.001$. 
Table 5

Study 2: Logistic Regression Analyses Predicting Choice of Interpersonal versus

Competence Feedback from Attachment and Self-Esteem

\begin{tabular}{|c|c|c|c|c|c|c|}
\hline \multirow[b]{2}{*}{ Model } & \multirow[b]{2}{*}{ Predictors } & \multicolumn{2}{|c|}{ Predictor } & \multirow{2}{*}{$\begin{array}{c}\text { Step } \\
\chi^{2}\end{array}$} & \multicolumn{2}{|c|}{ Overall Model } \\
\hline & & $B$ & $\begin{array}{l}\text { Odds } \\
\text { Ratio }\end{array}$ & & $-2 \mathrm{LL}^{\mathrm{a}}$ & $R^{2}$ \\
\hline \multicolumn{7}{|c|}{ Attachment } \\
\hline \multirow[t]{2}{*}{ Step 1} & Anxiety & $.45^{*}$ & 1.56 & $6.28^{*}$ & $139.71^{*}$ & .08 \\
\hline & Avoidance & -.21 & 0.81 & & & \\
\hline Step 2 & Anx $\times$ Avoid & -.13 & 0.88 & 0.71 & $139.01^{\dagger}$ & .08 \\
\hline \multicolumn{7}{|c|}{ Mediator } \\
\hline & Self-Esteem & -.52 & 0.59 & 2.75 & 143.24 & .03 \\
\hline
\end{tabular}

Notes. Anx = Anxiety; Avoid = Avoidance. Coefficients indicate effect of a predictor on likelihood of choosing interpersonal feedback. Coefficients for anxiety and avoidance did not alter in Step 2, so are omitted for brevity.

a $-2 \mathrm{LL}=-2 \log$ likelihood. Smaller values indicate better model fit.

${ }^{\dagger} p<.08,{ }^{*} p<.05$. 


\section{Figure Captions}

Figure 1. Simple slopes for positivity of selective feedback-seeking in the domains of relationships (left panel) and mastery (right panel) as a function of attachment anxiety and avoidance (Study 1).

Figure 2. Simple slopes for openness to feedback in the domain of social acceptance as a function of attachment anxiety and avoidance (Study 2). 
Figure 1

Relationships

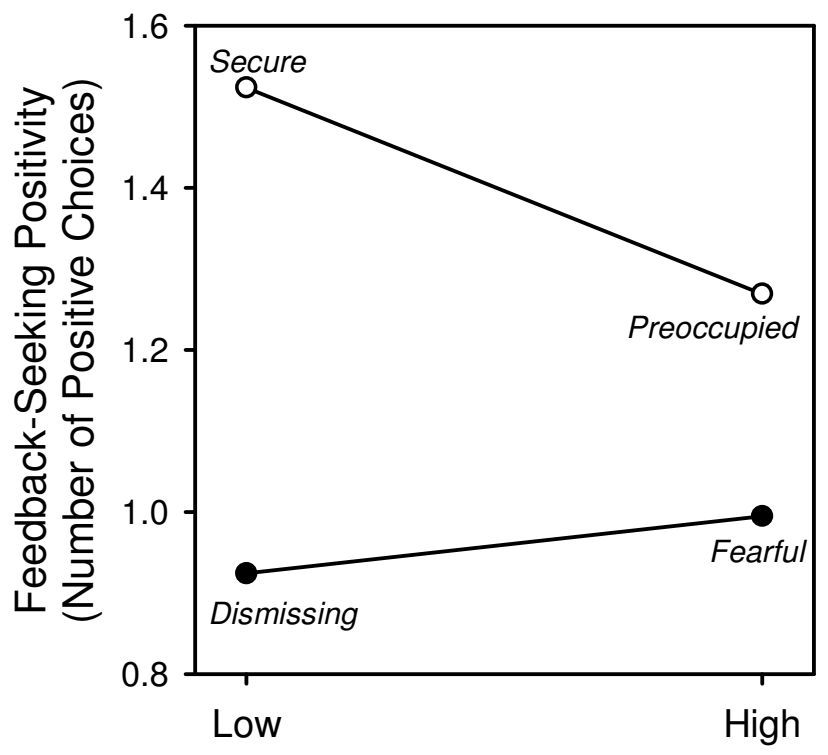

Mastery

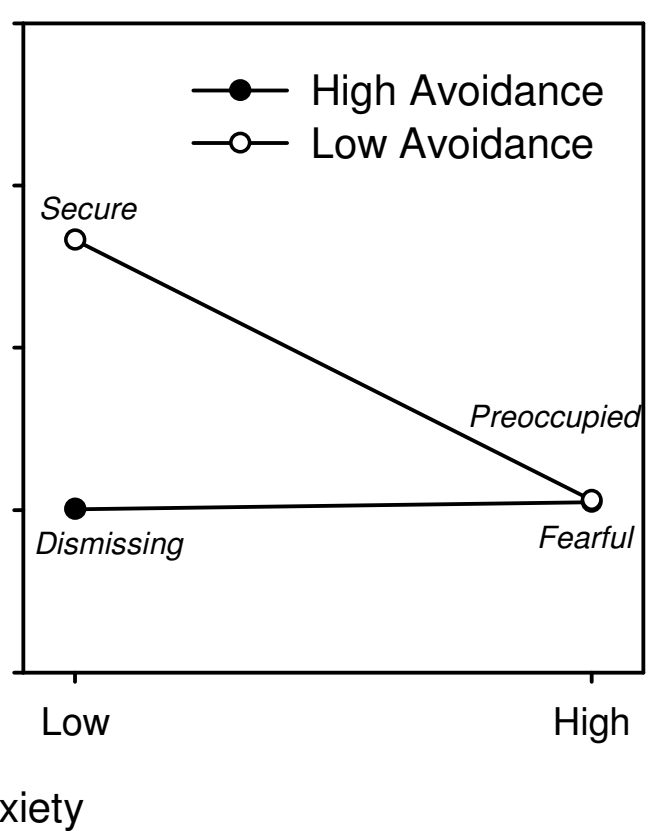


Figure 2

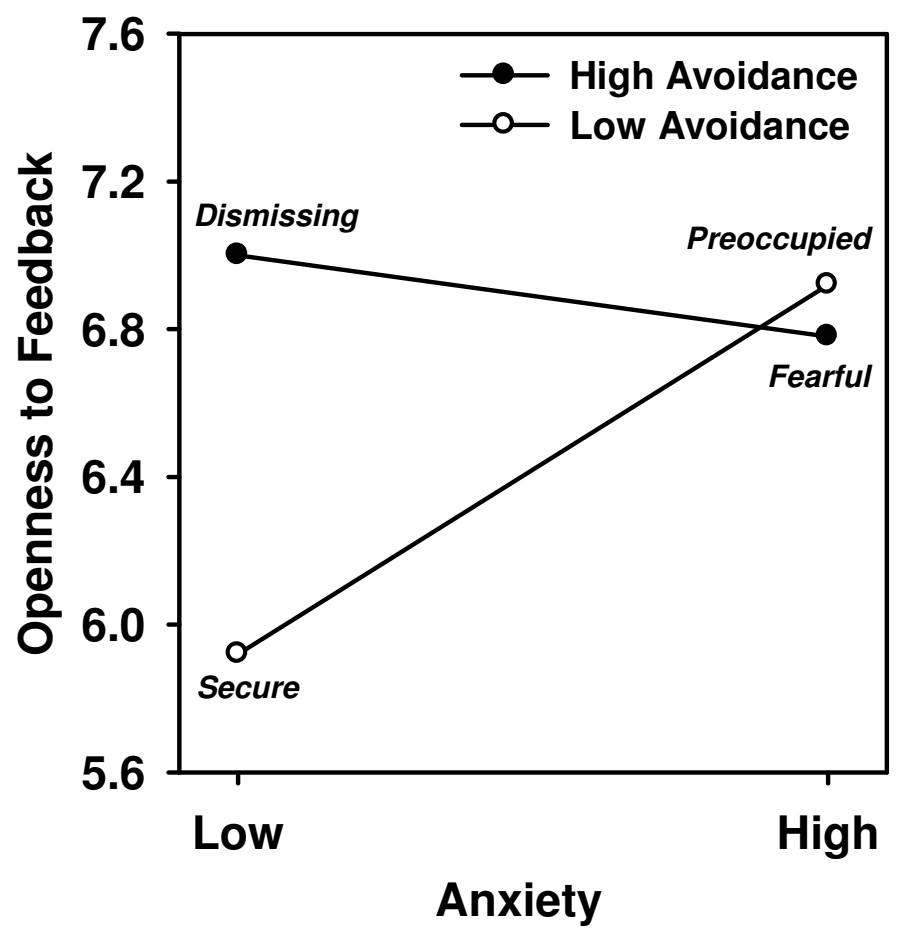

